\title{
Marching towards self-sufficiency in chickpea
}

\author{
G. P. Dixit, A. K. Srivastava* and N. P. Singh \\ ICAR-Indian Institute of Pulses Research, Kanpur 208 024, India
}

\begin{abstract}
Chickpea is a major pulse crop of India accounting for more than $40 \%$ of the total pulses area and production. From a mere 3.86 million tonnes $(\mathrm{mt})$ during 2000-01, chickpea production rose steadily to an alltime high of $11.23 \mathrm{mt}$ during 2017-18. The central and southern states such as Madhya Pradesh, Maharashtra, Rajasthan, Andhra Pradesh, Karnataka, Gujarat, Chhattisgarh and Jharkhand have benefited most from chickpea revolution in the country, with remarkable increase in both area and production. This has been achieved through development of suitable technologies like high-yielding varieties along with matching production and protection technologies, quality seed producing units, etc. To attain selfsufficiency by 2050 , the total pulse production in the country needs to reach $39 \mathrm{mt}$. This includes chickpea requirement of about $16-17.5 \mathrm{mt}$ by 2050 from an area of about $10.5 \mathrm{~m}$ ha with average productivity of 15-17 q/ha. The potential yield observed in AICRP (Chickpea) trials has increased from 10 to $17.50 \mathrm{q} / \mathrm{ha}$ during the past 20 years $(C A G R=1.51 \%)$. At this rate, the increased chickpea requirement can be easily achieved by 2050, provided there is proper policy backstopping. Here we review chickpea research in India during the last five decades and future research priorities to tackle newer challenges.
\end{abstract}

Keywords: Chickpea, improved varieties, production technologies, self-sufficiency.

CHICKPEA (Cicer arietinum L.) is widely cultivated in the world covering more than 50 countries spread over Asia, Africa, Europe, Australia, North America and South America. It is the second most important food legume crop after common bean (Phaseolus vulgaris L.) ${ }^{1}$. In India, chickpea is cultivated almost in all parts of the country mainly as a rainfed crop (68\% area) ${ }^{2}$. During 2017-18, chickpea production has been estimated to be about 11.23 million tonnes $(\mathrm{mt})$, which is $46 \%$ of the total pulses production $\left(23.95 \mathrm{mt}\right.$ ) in India $^{3}$. Among chickpea growing states, Madhya Pradesh, Maharashtra, Rajasthan, Uttar Pradesh, Andhra Pradesh, Karnataka, Chhattisgarh, Bihar and Jharkhand contribute more than $95 \%$ to the total production. In India, both desi and kabuli type chickpea varieties are grown. In recent years, the country has witnessed remarkable increase in area, production and productivity of chickpea.

*For correspondence. (e-mail: bhu.avinash@gmail.com)
India contributes to a major share of the world's chickpea area (70\%) and production (67\%) and continues to be the largest chickpea-producing nation. To meet domestic demand India also imports large quantities of desi chickpea. However, in the past decade, it has emerged as a major exporter of kabuli chickpea mainly to Pakistan, Algeria, Turkey, Sri Lanka, UAE, etc. India has made remarkable progress in expanding chickpea area and production. The area in the central and southern states has increased by about 3.5 million ha ( $\mathrm{m} \mathrm{ha}$ ) in the past two decades. This has helped the country in largely compensating the loss in chickpea area in northern India due to expansion of irrigated wheat cultivation.

Traditionally chickpea varieties cultivated in northern India required low temperature and prolonged winter for better growth. Hence chickpea cultivation was confined to the northern and central regions. With the intensification of wheat cultivation during rabi season due to the green revolution, the pulse area reduced in the northern states, especially where irrigation facilities were available. This has forced chickpea to shift to comparative warmer and harsher growing environment of the southern states. Development of short-duration chickpea varieties which are better adapted to warmer, short-season environments like central and southern India has helped in the establishment of chickpea as a rabi crop in these states.

Researchers across the National Agricultural Research System (NARS) have been instrumental in releasing a large number of chickpea varieties suitable for cultivation in different agro-ecological regions in the country. These varieties not only possess inherent resistance against important biotic and abiotic stresses, but also feature key market preference and altered phenology like large seeded desi types, adaptation to late sown condition, extra-large seeded kabuli types, high input responsiveness, salt tolerance, machine harvestable types, etc.

During the nineties, impetus was laid upon development of short-duration varieties with drought and heat tolerance, varieties with combined resistance against multiple diseases, high input responsive varieties, etc. Breeding for short duration (90-110 days) was directed towards environments where the growing season was short and escape from terminal drought and heat was essential for successfully raising a crop. Due to faster growth cycle, these varieties were able to provide yield equal to 
long-duration varieties, but in short-growth duration. Varieties like JG 11, Vijay, JG 16, Vikas, Vishal, JGK-1, KAK 2, ICCV 2 and ICCV-10 facilitated the expansion of chickpea in southern and central India. Similarly, in states such as Uttar Pradesh, Bihar, parts of Chhattisgarh, Jharkhand, Haryana and Punjab, where rice fields are vacated quite late after harvest of the crop, early maturing varieties amenable to late planting like Pusa 372, Udai, RSG 963, BGM 547 and Rajas were developed ${ }^{4}$. Later, large-seeded kabuli ( $>25 \mathrm{~g} / 100$ seeds) varieties like HK 05-169, GLK 26155, GNG 1969, GLK 28127 were developed after considering the consumer's preference for such types. This paved the way for development of extralarge seeded kabuli chickpea varieties with seed weight more than $50 \mathrm{~g} / 100$ seeds. Few varieties like Phule G 0517, PKV 4-1 and MNK-1 have been developed with seed size more than $50 \mathrm{~g} / 100$ seeds, which fetches premium price in the market. Also, varieties for specific conditions like CSG 8962 for mild salinity conditions of the North Western Plains, heat-tolerant JG 14 for central India and RSG 888 for cultivation in moisture stress or rainfed conditions of Rajasthan, Haryana and Punjab were developed. With increasing mechanization of farm operations for improving efficiency and reducing cost of cultivation in most crops, chickpea farmers are also demanding such cultivars which can be directly harvested by combine harvesters. Most of the present-day chickpea cultivars are not suited to machine harvesting because the plant height and architecture are not suitable for mechanized harvesting. Development of chickpea cultivars with tall $(>70 \mathrm{~cm})$ and erect growth habit is required. In recent years, few varieties like HC 5, GBM 2, NBeG 47, Phule Vikram, etc. have been developed which are amenable to machine harvesting 5 .

\section{Some success stories which brought about a major revolution in chickpea}

\section{Short-duration varieties for horizontal expansion}

In the past 4-5 decades, chickpea area has shifted from fertile regions of northern India to relatively harsher conditions in southern India. This necessitated the breeding of short-duration (90-110 days) varieties to suit the prevalent environment of the central and southern regions of the country having shorter chickpea growing window and persistent terminal drought and heat conditions. Development of short-duration varieties like JG 11, JAKI 9218, Vijay, Vikas, Vishal, JG 16, JG 14, JGK-1 and KAK 2 helped in increasing chickpea area in south and central India. These short-duration varieties provided comparable yield to long-duration varieties in shorter crop duration. In recent years, several short-duration varieties of chickpea, namely Rajas, Pusa 547, JAKI 9218, RVG 202, RVG 203, JGK 1, KAK 2 and Shubhra have been developed which suit these growing environments.

\section{Fusarium wilt resistant varieties}

Fusarium wilt is the most dreaded disease affecting chickpea crop in the whole country. Incorporation of disease resistance against Fusarium wilt in improved varieties has always been an important part of chickpea breeding programme. Many Fusarium wilt-resistant varieties have been developed which help in reducing losses due to diseases and provide stability to chickpea yield. Several chickpea varieties like JG 16, Digvijay, Gujarat Gram 3, BG 391, GNG 1581, CSJ 515, RVG 202, JGK 5, JG 6, Ujjawal, GLK 26155, HK 05-169, BDNG 797 and RSG 991 have been developed which possess resistance against Fusarium wilt, and released for cultivation in different parts of the country.

\section{Extra-large seeded kabuli varieties suitable for export}

In order to evolve large-seeded kabuli varieties, coordinated trials have been implemented since 1995-96 and as a result, varieties like BG 1003, BG 1053, Haryana Kabuli Chana 1, Haryana Kabuli Chana 2, KAK 2, JGK 1, Vihar and Virat were developed after considering the consumer's preference for large-seeded kabuli types. The seed size of these varieties ranged from 30 to $40 \mathrm{~g} / 100$ seeds. In order to tap the international market for kabuli types, special emphasis was laid for development of extra-large seeded kabuli chickpea varieties with seed size more than $50 \mathrm{~g} / 100$ seeds. A few varieties like Phule G 0517, PKV 4-1 and MNK-1 have been developed with seed size more than $50 \mathrm{~g} / 100$ seeds, which fetches premium price in the market. During 2011-16, 11.06 lakh tonnes of chickpea (mainly kabuli types) was exported to Pakistan, Algeria, Turkey, Sri Lanka, UAE, etc. This has helped the country earn about Rs 6116.30 crores during 2012-17 (ref. 6).

\section{Varieties suitable for late sown conditions}

The chickpea area in northern and eastern India has reduced drastically over the years mainly due to competition with irrigated wheat crop. In Uttar Pradesh, Bihar, parts of Chhattisgarh, Jharkhand, Haryana and Punjab where rice fields are vacated quite late after harvest of the crop, early maturing varieties amenable to late planting are needed. Identification of chickpea varieties suitable for late planting (KPG 59, BG 372, Pant G 114, Pant G 186, Rajas, BGM 547) has led to diversification of the rice-wheat system, particularly in the tail end of command areas of northern and eastern India, where irrigation is not enough to support a good crop of wheat. Early maturing varieties like JG 14, RVG 202, RVG 203, etc. are suitable for cultivation in the eastern parts of central India under late sown condition. Planting of chickpea on 
raised beds in rice fields is as profitable as the rice-wheat system. Cultivation of chickpea has been estimated to provide considerable nitrogen $(30-40 \mathrm{~kg} / \mathrm{ha})$ to the succeeding crop.

\section{Biotic and abiotic stress-resistant varieties}

Chickpea is affected by many biotic (diseases like wilt, dry root rot, ascochyta blight, botrytis grey mould, etc.) and abiotic (heat, drought, cold, salinity, etc.) stresses during crop duration. It is estimated that on an average chickpea suffers a loss to the tune of $25-30 \%$ to various biotic and abiotic stresses. Incorporation of disease resistance in improved varieties has always been an important part of chickpea breeding programmes. Several chickpea varieties have been developed which possess resistance against various biotic and abiotic stresses, and released for cultivation in different regions/states. Many varieties tolerant to ascochyta blight, namely GNG 469, Himachal Chana 1, PBG 5, RSG 807, GJG 0809, etc. are developed for North West Plains Zone (Punjab, Haryana, northwestern Rajasthan and western Uttar Pradesh). Recently, dry root rot has emerged as a major problem in chickpeagrowing areas, especially under rainfed condition. Chickpea varieties like RSG 974, RVG 202, CSJ 515, CSJ 140, JGK 5, JG 6 and RSG 959, etc. possess tolerance to dry root rot and can be grown in such areas. Besides, many abiotic stress-tolerant varieties have been developed. These include heat-tolerant, short-duration varieties for late sown condition (JG 14, JSC 55, JSC 56), droughttolerant varieties for rainfed conditions (RSG 888, Vijay), varieties that can tolerate mild salinity (Karnal Chana 1) as well as varieties for high input condition of increased moisture and soil fertility (DCP 92-3).

\section{Impact of newer technologies on the Indian chickpea scenario}

Chickpea is cultivated in 25 states of India, with the major ones like Madhya Pradesh, Maharashtra, Rajasthan, Karnataka, Uttar Pradesh, Andhra Pradesh, Chhattisgarh,

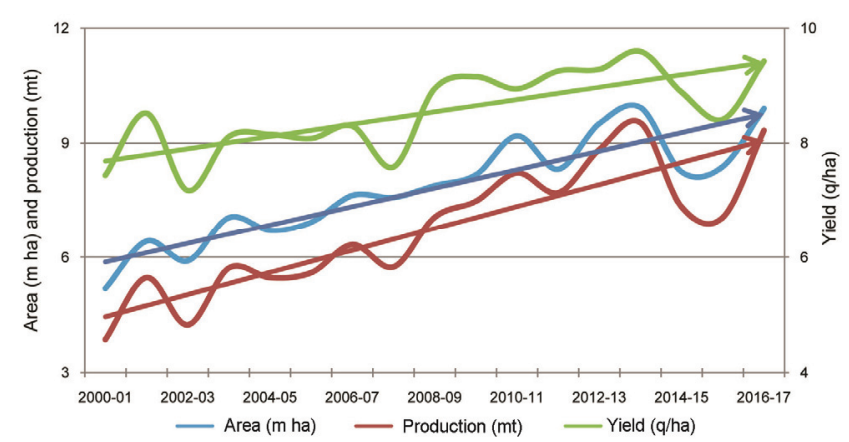

Figure 1. Area, production and yield of chickpea during 2000-01 to 2016-17 in India.
Gujarat and Jharkhand constituting more than $96 \%$ of area under chickpea. Research efforts made through NARS have led to the development of more than 200 varieties of chickpea which are adapted to varying agro-climatic conditions having in-built resistance against key biotic and abiotic stresses. Simultaneously, matching production and protection technologies have also been developed. As a result of all these efforts, the area under cultivation for chickpea has been increased from about $5.19 \mathrm{~m}$ ha in $2000-01$ to $10.76 \mathrm{~m}$ ha in 2017-18. This is coupled with increase in production $(3.86 \mathrm{mt}$ in $2000-01$ to $11.1 \mathrm{mt}$ in 2017-18) and productivity (7.44 q/ha in $2000-01$ to $10.31 \mathrm{q} /$ ha in 2017-18) of chickpea as well (Figure 1).

\section{Future research strategies}

In India, chickpea will continue to be an important pulse crop in the future as well. There is ample scope and opportunity for increasing area, production and productivity of chickpea in India by way of adopting suitable research, development and related policies. The insulation of varieties against major biotic stresses like Fusarium wilt, ascochyta blight, botrytis grey mould, dry root rot, and collar rot and abiotic stresses like heat, cold, frost, salinity and drought needs to be addressed according to the needs of the specific agro-climatic conditions/zones. Improved plant types amenable to mechanical operations, i.e. cultural operation, harvesting and post-harvest operations will be the need of the future. Early maturing genotypes are likely to enjoy farmers' favour in view of depleting sources of irrigation in rainfed areas. Reintroduction of chickpea in cereal-cereal rotation as pure or inter-crop and mixed crop may require restructuring the genotypes to suit the specific niches.

Chickpea improvement programmes need to be dynamic and efficient in rapidly developing varieties needed for adaptation in existing and evolving cropping systems, and have the traits preferred by farmers, industries and consumers. Also, there is a need to consider the environment and efficiency in the use of available resources. Traits like phosphorus acquisition efficiency and biological nitrogen fixation efficiency need due consideration. Though chickpea is a good source of proteins, carbohydrates, dietary fibre, minerals ( $\mathrm{Fe}, \mathrm{Zn}, \mathrm{Ca}$ and $\mathrm{Mg}$ ) and other important nutrients that are essential for human health $^{7}$, there is scope for further improving the nutritional quality of chickpea. Protein content of present-day cultivars is usually in the range $18-22 \%$ whereas much larger variability (14-32\%) exists in the germplasm which could potentially be exploited to develop highprotein $(\geq 25 \%)$ varieties. Similarly, wide variation has been observed for iron and zinc contents in the germplasm, which can be exploited for developing varieties having high iron and zinc content. It is important to develop nutritionally enhanced varieties as consumers 


\section{REVIEW ARTICLE}

would get a higher amount of protein and other nutrients from the same amount of chickpea consumed.

With the development of abundant chickpea genomic resources during the past decade, it has been now possible to incorporate genomics-assisted breeding tools for chickpea improvement in general breeding programmes. This is particularly important for breeding for abiotic and biotic stress resistance. Integrating breeding approaches utilizing conventional and genomic resources would lead to speedy, precise and efficient chickpea breeding. Marker associated selection (MAS) for chickpea improvement is being followed for improving drought tolerance using 'QTL hotspot' gene ${ }^{8}$, heat stress tolerance, enhancing genetic diversity through multi-parent advanced generation intercrossing (MAGIC) lines, introgressing disease resistance like wilt and ascochyta blight, etc. Pod borer (Helicoverpa armigera) continues to remain the most challenging insect-pest of chickpea due to non-availability of sources with high levels of resistance in germplasm. Development of transgenic varieties against gram pod borer (Helicoverpa armigera Hubner) using different Cry genes (Bt genes) is in progress at many public-funded institutions, including ICAR-Indian Institute of Pulses Research (ICAR-IIPR), Kanpur and private companies. Scientists at ICAR-IIPR have performed insect bioassay and molecular characterization of transgenic plants carrying $B t$ gene in chickpea using different techniques. Similarly, $D R E B$ genes are being utilized to develop transgenic varieties against drought stress at several public and private funded institutions in India. Availability of draft genome sequence and resequencing of several germplasm lines, including popular varieties have opened up the possibility of utilizing advanced genome editing tools like CRISPR-Cas9 system in chickpea. There are no reports on the use of CRISPR-Cas9 system in chickpea, although the system was shown to be effective in mushroom, maize, wheat, tomatoes, rice, coffee, grapes and banana. In most cases, gene knock-out was the main target to improve trait. In chickpea the negative regulator of the biosynthetic pathway, susceptibility of disease resistance may be targeted for genome editing.

Several studies have indicated the role of soil microbiota in managing soil pathogens in suppressive soils. Differences have been observed among genotypes of chickpea for their ability to alter soil microbiome ${ }^{9}$, which opens another dimension for selecting chickpea genotypes enabling beneficial soil biotic environment. This needs to be explored further to select cultivars that improve rhizosphere health leading to efficient use of soil resources.

\section{Policy backstopping}

Upscaling of research findings to farmers' fields essentially requires enabling policy environment to have sig- nificant impact. During the XI Plan period, several programmes like the National Food Security MissionPulses, Accelerated Pulses Production Programme and Rashtriya Krishi Vikas Yojna, 60,000 Pulses Villages, were launched to boost pulses production in the country with technological back-up and interventions of NARS and well-planned financial support by the Planning Commission and Ministry of Agriculture, Government of India. Policy initiatives such as increasing the minimum support price by the Government also encouraged the farmers to take up pulse cultivation as a profitable venture. To sustain production, several steps are still required. These include assured procurement and inclusion of pulses in the public distribution system, lucrative minimum support price (MSP) to make pulses comparable to cereals, buffer stock to meet any contingent condition, strict imposition of holding limit of pulses with traders, extending the benefit of crop insurance schemes to pulses, proper infrastructure for safe storage and postharvest processing.

1. Gaur, P. M. et al., Climate change and heat stress tolerance in chickpea. In Climate Change and Plant Abiotic Stress Tolerance, Vol. 2 (eds Tuteja, N. and Gill, S. S.), Wiley-VCH Verlag GmbH \& Co KGaA, Weinheim, Germany, 2000, pp. 839-855.

2. DAC, Agricultural Statistics at a Glance 2016, Department of Agriculture, Cooperation \& Farmer's Welfare, Directorate of Economics and Statistics, Ministry of Agriculture and Farmers' Welfare, Government of India 2016, p. 519; http://eands.dacnet.nic.in/PDF/ Glance-2016.pdf

3. Anon., 4th Advance estimate of Production of Foodgrains for 2017 18. Directorate of Economics \& Statistics, Department of Agriculture, Cooperation and Farmers' Welfare, Ministry of Agriculture and Farmers' Welfare, Government of India, 2018; https:// eands.dacnet.nic.in/Advance Estimate/4th_Adv Estimates2017-18 Eng.pdf (accessed on 17 October 2018).

4. Dixit, G. P., Project Coordinator's Report, All India Coordinated Research Project on Chickpea, Indian Institute of Pulses Research, Kanpur, 2016.

5. Chaturvedi, S. K., Mishra, N. and Gaur, P. M., An overview of chickpea breeding programs in India. Legume Perspect., 2015, 3, 50-52.

6. Agricultural and Processed Food Products Export Development Authority, Ministry of Commerce and Industry, Government of India, 2018; http://agriexchange.apeda.gov.in/indexp/Product_description. aspx?hscode $=07132000$ (accessed on 30 January 2018).

7. Jukanti, A. K., Gaur, P. M., Gowda, C. L. L. and Chibbar, R. N., Nutritional quality and health benefits of chickpea (Cicer arietinum L.): a review. Br. J. Nutr., 2012, 108(S1), S11-S26.

8. Varshney, R. K. et al., Genetic dissection of drought tolerance in chickpea (Cicer arietinum L.). Theor. Appl. Genet., 2014, 127, 445462.

9. Ellouze, W., Hamel, C., Vujanovic, V., Gan, Y. T., Bouzid, S. and St-Arnaud, M., Chickpea genotypes shape the soil microbiome and affect the establishment of the subsequent durum wheat crop in the semiarid North American Great Plains. Soil Biol. Biochem., 2013, 63, 129-141; doi:10.1016/j.soilbio.2013.04.001.

Received 5 April 2018; revised accepted 20 October 2018

doi: $10.18520 / \mathrm{cs} / \mathrm{v} 116 / \mathrm{i} 2 / 239-242$ 